Scientia Agricola

http://dx.doi.org/10.1590/0103-9016-2015-0047

\title{
Relationships between labile soil organic carbon fractions under different soil management systems
}

\author{
Géssica Pereira de Souza ${ }^{1}$, Cícero Célio de Figueiredo ${ }^{*}$, Djalma Martinhão Gomes de Sousa ${ }^{2}$
}

'University of Brasilia/FAV/Central Institute of Sciences, Campus Darcy Ribeiro - 70910-970 - Brasília, DF - Brazil. 2Embrapa Cerrados, BR 020, km 18 - 73310-970 -

Planaltina, DF - Brazil.

*Corresponding author <cicerocf@unb.br>

Edited by: Carlos Eduardo Pellegrino Cerri

\begin{abstract}
The study of labile carbon fractions (LCF) provides an understanding of the behavior of soil organic matter (SOM) under different soil management systems and cover crops. The aim of this study was to assess the effect of different soil management systems with respect to tillage, cover crop and phosphate fertilization on the amount of the LCF of SOM. Treatments consisted of conventional tillage (CT) and no-tillage (NT) with millet as the cover crop and a no-tillage system with velvet bean at two phosphorus dosages. Soil samples were collected and analyzed for organic carbon $(\mathrm{OC}), \mathrm{C}$ oxidizable by $\mathrm{KMnO}_{4}\left(\mathrm{C}-\mathrm{KMnO}_{4}\right)$, particulate $\mathrm{OC}(\mathrm{POC})$, microbial biomass carbon and light SOM in the 0.0-0.05, 0.05-0.10 and 0.10-0.20 m soil layers. The Carbon Management Index (CMI) was calculated to evaluate the impacts of soil management treatments on the quality of the SOM. The different LCFs are sensitive to different soil management systems, and there are significant correlations between them. $\mathrm{C}-\mathrm{KMnO}_{4}$ is considered the best indicator of OC carbon lability. In the soil surface layers, the $\mathrm{CT}$ reduced the carbon content in all of the labile fractions of the SOM. The use of phosphorus led to the accumulation of $\mathrm{OC}$ and carbon in the different soil fractions regardless of the tillage system or cover crop. The application of phosphate fertilizer improved the ability of the NTsystem to promote soil quality, as assessed by the CMI. Keywords: labile organic matter, soil organic matter, phosphorus fertilization
\end{abstract}

Received February 04, 2015

Accepted March 06, 2016 organic carbon fraction was different from one to the other (Quanying et al., 2014). To resolve such issues, the carbon management index (CMI) has been used as a tool fort determining the state and rate of change in soil $\mathrm{C}$ of land use systems in an integrated manner (Blair et al., 1995; Nogueirol et al., 2014).

We hypothesized that (i) the tillage system impacts the labile SOM fraction more strongly than the soil organic carbon $(\mathrm{OC})$; (ii) positive correlations are present between the various labile fractions; (iii) phosphorus fertilization and a no-tillage system promote the accumulation of SOM and an increase in the CMI. Our goal was to assess the effect of soil management with respect to tillage, cover crop and phosphate fertilization on the amount of the labile carbon fractions of the SOM in the Cerrado.

\section{Materials and Methods}

Location and characteristics of the experimental area The study was carried out in an experimental area of Embrapa Cerrados, in Planaltina, DF, Brazil $\left(15^{\circ} 36^{\prime}\right.$ $\mathrm{S}, 47^{\circ} 42^{\prime} \mathrm{W}$ and an altitude of $\left.1.014 \mathrm{~m}\right)$. The climate is Cwa according to Köppen's classification (Alvares et al., 2013), with a mean annual temperature and precipitation of $21.3^{\circ} \mathrm{C}$ and $1,570 \mathrm{~mm}$, respectively. The soil was categorized as an Acrustox according to the Soil Taxonomy classification (Soil Survey Staff, 2006), with the relief characterized as gently undulating, $3 \%$ slope, and the contents of clay, silt and sand are 571, 72 and $357 \mathrm{~g} \mathrm{~kg}^{-1}$, respectively.

The area was deforested in 1976 and was used for pasture and grain production for 20 years. In 1996, prior to sowing soybean, limestone was applied to decrease 
soil acidity and increase grain yield. In the same agricultural year of 1996 and the following year (1997/98), soybeans were planted and $80 \mathrm{~kg} \mathrm{ha}^{-1}$ of $\mathrm{P}_{2} \mathrm{O}_{5}$ were applied in the planting furrow; $80 \mathrm{~kg} \mathrm{ha}^{-1}$ of $\mathrm{K}_{2} \mathrm{O}$ as potassium chloride and $30 \mathrm{~kg} \mathrm{ha}^{-1}$ of sulfur (S) as gypsum were broadcasted on the soil surface. In 1998/99, corn was grown in the area, and $80 \mathrm{~kg} \mathrm{ha}^{-1}$ of $\mathrm{K}_{2} \mathrm{O}, 30 \mathrm{~kg} \mathrm{ha}^{-1}$ of $\mathrm{S}$ and $150 \mathrm{~kg} \mathrm{ha}^{-1}$ of urea $\mathrm{N}$, without phosphorus, were applied at planting. These three crops were grown to gain knowledge about the variability of the area so that the proper experimental design might be selected, and to obtain high soil fertility for the study of $\mathrm{P}$ management.

The experiment began in 1999 when the treatments of phosphorus $(\mathrm{P})$ rates were established. The soil chemical conditions were appropriate, due to the cornsoybean succession, and winter cover crops were sown at the end of the rainy season and remowed at the time of flowering. In 2008 and 2009, the cover crops were fertilized with $45 \mathrm{~kg} \mathrm{ha}^{-1}$ of urea $\mathrm{N}$ to increase the production of plant biomass.

Because of a common phenomenon in the region called "veranico" (mid-summer drought), the soybean and corn crops received supplemental sprinkler irrigation in drought situations during the rainy season. The irrigation was controlled by tensiometers installed in plots at a depth of $0.20 \mathrm{~m}$ and started when the soil water tension reached $45 \mathrm{kPa}$. The cover crops were also irrigated in the winter.

\section{Experimental design and soil sampling}

The experimental layout consisted of a randomized block design with split plots. Three management systems were randomly assigned to the plots and the $\mathrm{P}$ rates were assigned to the subplots.

The following management systems were studied: 1) a conventional tillage system consisting of plowing and harrowing before planting, with millet (Pennisetum glaucum) as the cover crop (CTml); 2) a no-tillage system with millet coverage (NTml); and 3) no-tillage with velvet beans (Mucuna aterrima) as the cover crop (NTmc). Treatments with no P fertilization (P0) and with $100 \mathrm{~kg}$ ha-1 $\mathrm{yr}^{-1}$ of $\mathrm{P}_{2} \mathrm{O}_{5}$ as granular triple super phosphate (P1) were used in the planting furrow.

Soil samples were collected in Mar 2010, during the filling of soybean grain, at depths of $0.0-0.05 ; 0.05-0.10$ and $0.10-0.20 \mathrm{~m}$ using an auger that was $0.05 \mathrm{~m}$ in diameter. One composite sample per plot was collected, which was formed by 20 subsamples (four locations within each plot $\times$ five subsamples per location - one on the line and four on the equidistant inter-row spacings). The soil was homogenized and separated for chemical analysis, airdried and passed through a sieve of $2 \mathrm{~mm}$ or $0.5 \mathrm{~mm}$.

Soil samples were collected at the same depths as in the experimental area in an area under native Cerrado vegetation that was close to the experimental plots, and these were used as reference samples. The soil samples were collected from 20 random points in two different places.

\section{Organic carbon and fractionation of organic matter} Organic carbon (OC) was determined by wet oxidation with potassium dichromate $\left(10 \mathrm{~mL}\right.$ of $0.167 \mathrm{~mol} \mathrm{~L}^{-1}$ $\left.\mathrm{K}_{2} \mathrm{Cr}_{2} \mathrm{O}_{7}\right)$ in sulfuric acid $\left(20 \mathrm{~mL} \mathrm{H}_{2} \mathrm{SO}_{4}\right)$ without an external heat source, followed by titration with $0.4 \mathrm{~mol} \mathrm{~L}^{-1}$ $\mathrm{Fe}\left(\mathrm{NH}_{4}\right)_{2}\left(\mathrm{SO}_{4}\right)_{2} \cdot 6 \mathrm{H}_{2} \mathrm{O}$ (Walkley and Black, 1934). The various labile fractions were determined by four different methods described below.

- For particulate organic carbon (POC), the organic matter was physically fractionated according to Cambardella and Elliot (1992). After air-drying, subsamples were sieved through a $2 \mathrm{~mm}$ sieve. Twenty grams of each subsample were placed in a $250 \mathrm{~mL}$ plastic bottle and $70 \mathrm{~mL}$ of sodium hexametaphosphate at a concentration of $5.0 \mathrm{~g} \mathrm{~L}^{-1}$ was added. The mixture was shaken for $15 \mathrm{~h}$ in a horizontal shaker, at 130 oscillations per $\mathrm{min}^{-1}$. After this process, the entire contents of the vial were placed in a $53 \mu \mathrm{m}$ sieve and washed with a weak jet of distilled water. The material retained in the sieve, which consisted of particulate organic carbon (POC > $53 \mu \mathrm{m}$ ) was oven dried at $50{ }^{\circ} \mathrm{C}$ to constant weight and then milled in a mortar until it could be passed through a $0.149 \mathrm{~mm}$ sieve, for the assessment of the total organic $\mathrm{C}$ content of the particulate fraction by dry combustion in a $\mathrm{CHNS/O}$ analyzer.

- For the carbon in the light fraction of the organic matter (CMOL), the carbon content was obtained by separation of the light fraction organic matter (LFOM) with 2 mol L-1 phosphoric acid followed by agitation and centrifugation according to Schiavo et al. (2009). The material retained on the filter after the supernatant had been filtered was the LFOM. Based on the LFOM values, the $\mathrm{C}$ content of this fraction was calculated by multiplying the LFOM by 0.58 (Van Bemmelen factor) because, on average, $58 \%$ of the SOM is C (Nelson and Sommers, 1996).

- For $\mathrm{C}-\mathrm{KMnO}_{4}$, the $\mathrm{C}$ oxidizable by a solution of $\mathrm{KMnO}_{4}$ $0.033 \mathrm{~mol} \mathrm{~L}^{-1}$ was determined according to Blair et al. (1995). For this purpose, $1 \mathrm{~g}$ of air-dried fine earth (ADFE) sieved with a $0.5 \mathrm{~mm}$ mesh was agitated and centrifuged with $25 \mathrm{~mL}$ of a solution of $0.033 \mathrm{~mol} \mathrm{~L}^{-1}$ $\mathrm{KMnO}_{4}$. After centrifugation, $1 \mathrm{~mL}$ of the supernatant was pipetted into a $250 \mathrm{~mL}$ volumetric flask and made up to volume with distilled water. Absorbance at 565 $\mathrm{nm}$ was determined with a spectrophotometer. The change in the concentration of $\mathrm{KMnO}_{4}$, estimated from an analytical curve with known $\mathrm{C}$ values, was used to estimate the amount of oxidized $\mathrm{C}\left(\mathrm{C}-\mathrm{KMnO}_{4}\right)$, considering that $1.0 \mathrm{mmol}$ of $\mathrm{Mn}$ is consumed in the oxidation of $0.75 \mathrm{mmol}$ (9 $\mathrm{mg}$ ) of C.

- Microbial biomass carbon (MBC) was determined by the fumigation-extraction method, according to Vance et al. (1987). Six 20-g soil subsamples of each field sample were weighed in triplicate with the water content adjust- 
ed to equilibrium at a tension of $0.03 \mathrm{MPa} / \sim 80 \%$ of the soil field capacity). These samples were pre-incubated at room temperature $\left(26 \pm 2^{\circ} \mathrm{C}\right)$ for 7 days in capped $600 \mathrm{~mL}$ containers kept in the dark. Then, three subsamples were fumigated $(\mathrm{F})$ for $24 \mathrm{~h}$ in a drier containing a Petri dish with $25 \mathrm{~mL}$ of chloroform without ethanol $\left(\mathrm{CHCl}_{3}\right)$. The other, non-fumigated $(\mathrm{NF})$, subsamples were kept at room temperature. After fumigation, the $\mathrm{F}$ and NF subsamples were shaken on a horizontal shaker (150 rpm) for $30 \mathrm{~min}$ with $50 \mathrm{~mL}$ of the extraction solution $\left(0.5 \mathrm{M} \mathrm{K}_{2} \mathrm{SO}_{4}\right)$. Subsequently, the subsamples were filtered through qualitative filter paper. The MBC was determined according to Vance et al. (1987), using an $8 \mathrm{~mL}$ aliquot of the filtered extract and was determined as the difference between the $\mathrm{C}$ extracted from the $\mathrm{F}$ and NF soil samples using a correction factor $\left(\mathrm{k}_{\mathrm{C}}\right)$ of 0.35 (Joergensen, 1996).

\section{Carbon Management Index (CMI)}

The CMI was calculated at the $0-0.10 \mathrm{~m}$ soil depth according to the mathematical procedures proposed by Blair et al. (1995) as follows:

$\mathrm{CMI}=$ Carbon Pool Index $(\mathrm{CPI}) \times$ Lability Index $(\mathrm{LI})$ $\times 100$

where CPI is the carbon pool index and LI the lability index.

The CPI and the LI are calculated as follows:

$\mathrm{CPI}=\mathrm{C}$ pool in treatment $/ \mathrm{C}$ pool in reference, $\mathrm{LI}=\mathrm{L}$ in treatment $/ \mathrm{L}$ in reference.

where $\mathrm{L}$ refers to the $\mathrm{C}$ lability calculated as: $\mathrm{L}=$ content of labile $\mathrm{C} /$ content of non-labile $\mathrm{C}$.

The native Cerrado was used as the reference, with the CMI defined as 100 . The labile $\mathrm{C}$ was considered as the $\mathrm{C}-\mathrm{KMnO}_{4}$. The non-labile $\mathrm{C}$ content was estimated from the difference between the TC and the labile C (Blair et al., 1995).

\section{Statistical analysis}

The levels of OC and the different labile fractions were statistically analyzed using the SAS 9.1 software. For analysis of variance, the OC, POC, CMOL, C-KM$\mathrm{nO}_{4}$ and $\mathrm{MBC}$ levels were compared for each soil layer. Where the analysis of variance indicated significance, Tukey's test $(p<0.05)$ was used to test for differences between the means.

\section{Results and Discussion}

\section{Effect of management systems on soil organic carbon}

The analysis of variance for the OC content indicated that only the effect of the management system was significant (Table 1). The management systems reduced the soil organic carbon in relation to the native Cerrado vegetation, especially in CTml, with losses of $37 \%, 18$
Table 1 - Total organic carbon content in different layers of an Oxisol cultivated for 11 years in a corn-soybean succession under different management systems and native Cerrado vegetation as reference.

\begin{tabular}{lllll}
\hline \multirow{2}{*}{ Depth $(\mathrm{m})$} & NT velvet bean & NT millet & CT millet & Cerrado \\
\cline { 2 - 5 } & \multicolumn{4}{c}{$\mathrm{g} \mathrm{kg}^{-1}$} \\
\hline $0.0-0.05$ & $20.56 \mathrm{~B}$ & $22.51 \mathrm{~A}$ & $16.01 \mathrm{C}$ & 25.38 \\
$0.05-0.10$ & $16.52 \mathrm{AB}$ & $17.94 \mathrm{~A}$ & $15.71 \mathrm{~B}$ & 19.11 \\
$0.10-0.20$ & $13.22 \mathrm{~B}$ & $14.23 \mathrm{~A}$ & $14.49 \mathrm{~A}$ & 15.76 \\
\hline
\end{tabular}

CT: Conventional tillage system; NT: no-tillage system. Values followed by the same letter in the line do not differ by Tukey's test $(p<0.05)$.

$\%$ and $8 \%$, in the $0.0-0.05 ; 0.05-0.10$ and $0.10-0.20 \mathrm{~m}$ layers, respectively (Table 1). A similar finding was obtained by Rangel et al. (2008) that reported a decrease in the OC level at the 0.0-0.10 m depth compared to the natural system for all systems of soil uses and managements. However, the NTml was found to be most closely related to the accumulation of $\mathrm{OC}$ in the soil of the native Cerrado, demonstrating the potential of this system to produce grain with a reduced impact on the soil carbon balance. This pattern of behavior of the OC in NT is well established and is caused by the absence of mechanical incorporation of the crop residue (Figueiredo et al., 2013), followed by a pronounced increase in root growth in the upper layers of the soil, compared to CT (Nunes et al., 2011).

In the layers assessed, the conventional tillage system resulted in further reductions in the organic carbon level, even when millet was used as the cover crop, due to the more rapid decomposition of the SOM promoted by soil disturbance (Nunes et al., 2011). Furthermore, the results showed that for tropical climatic conditions which favor the rapid decomposition of the crop residue, the transformation of natural vegetation in the agro-ecosystems under conventional tillage promotes a reduction in SOM mainly in the topsoil.

\section{Labile fractions of organic matter affected by soil} management systems

The levels of carbon in the labile fractions were affected by the management system and $\mathrm{P}$ rates (Figures $1 \mathrm{~A}$ and $\mathrm{B}$ ). However, the interaction system $\times \mathrm{P}$ rate was not significant.

In the 0.0-0.05 $\mathrm{m}$ layer, the no-tillage systems showed higher $\mathrm{C}-\mathrm{KMnO}_{4}$ contents than $\mathrm{CTml}$, indicating that plowing and harrowing can reduce crop residues on the soil surface, and have a direct impact on the most easily oxidized SOM fractions. In the 0.05-0.10 and 0.10-0.20 m layers, no differences were evident in C$\mathrm{KMnO}_{4}$ content between the soil management systems. Of the various fractions analyzed by Plaza-Bonilla et al. (2014), C- $\mathrm{KMnO}_{4}$ presented the greatest difference between management systems, with an increase of $54 \%$ in a no-tillage system compared to conventional tillage. These findings demonstrate that this fraction responds to the management system and is related to the organic 
matter deposited on the surface of the soil as the crop residue, as well as to the greater development of the crop root system in the upper soil layers.

The levels of particulate organic carbon (POC) ranged from 0.94 to $10.56 \mathrm{~g} \mathrm{~kg}^{-1}$ of soil (Figure 2A); these levels were close to those found by other authors in studies conducted in Cerrado areas, in clayey and very clayey soils (Figueiredo et al., 2010). The simple effects of soil tillage system and phosphorus rates were significant $(p<0.05)$ for this parameter.

There was a difference in POC between management systems and cover crops, but this difference was restricted to the 0.0-0.05 and 0.10-0.20 m layers. In the upper layer, the no-tillage systems had a higher POC content than the CTml, and NTmc was higher than NTml. The highest input of biomass occurred with millet compared to velvet bean, and the lesser soil disturbance due to NT explains these differences, stressing the importance of minimal soil disturbance for the accumulation

$$
\mathrm{C}-\mathrm{KMnO}_{4}\left(\mathrm{~g} \mathrm{~kg}^{-1}\right)
$$
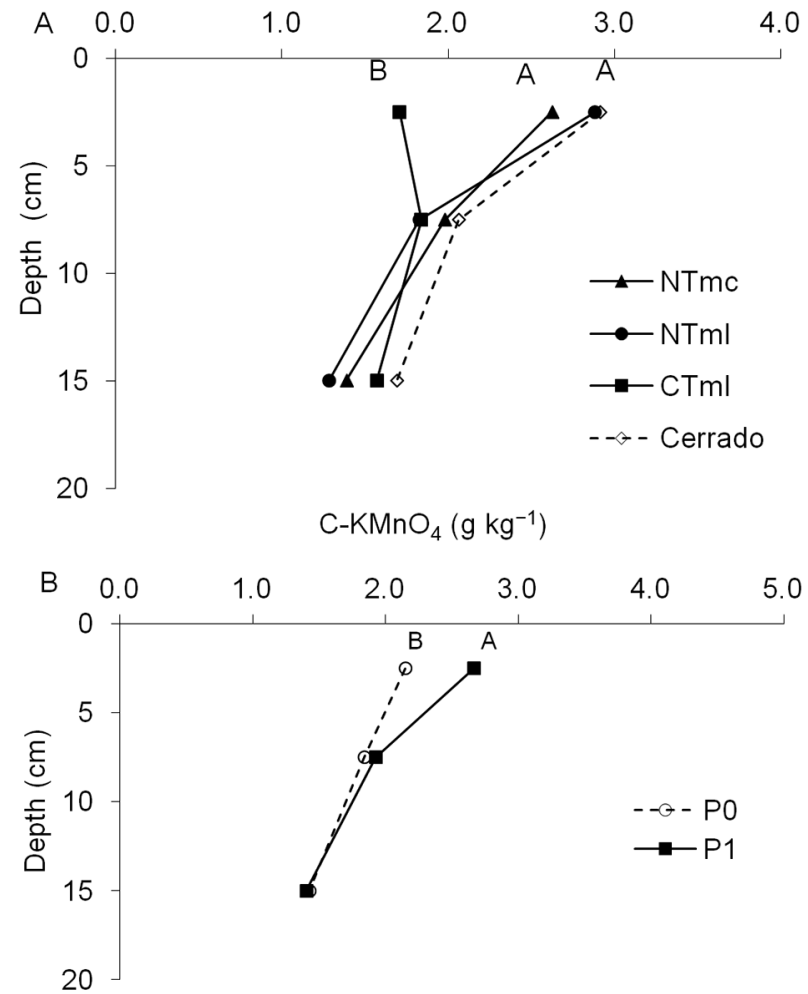

Figure 1 - Distribution of oxidizable $\mathrm{C}$ by a $\mathrm{KMnO}_{4} 0.033 \mathrm{~mol} \mathrm{~L}^{-1}$ $\left(\mathrm{C}-\mathrm{KMnO}_{4}\right.$ ) solution as a function of soil depth of an Oxisol under different management systems (A) (conventional tillage system with millet - CTml, no-tillage system with millet - NTml, no-tillage system with velvet bean - NTmc and native Cerrado vegetation as reference) and doses of phosphorus (B) (PO and P1: 0 and $100 \mathrm{~kg}$ ha- ${ }^{-1} \mathrm{yr}^{-1}$ of $\mathrm{P}_{2} \mathrm{O}_{5}$, respectively). Means with equal letters between systems and $\mathrm{P}$ doses at the same depth do not differ by Tukey's test $(p<0.05)$. of $\mathrm{C}$ in the particulate fractions of the SOM, which represents the principal substrate that ensures the mineralization of nutrients by the soil microbiota (Figure 2A). The presence of C-carbohydrates rather than C-polyphenols in the larger fractions $(2000-50 \mathrm{~mm})$ indicates the highly labile characteristics of such fractions (Rovira et al., 2010). Moreover, this behavior demonstrates that the variation in POC content depends on the species under cultivation (Loss et al., 2014). Because it is labile (Rovira et al., 2010), this organic matter $\mathrm{C}$ fraction can quickly decompose, and constitutes a transient $\mathrm{C}$ reserve in the soil.

$\mathrm{P}$ application also increased the POC level in the upper layer, even though the soil showed adequate and appropriate $\mathrm{P}$ values at the beginning of the experiment (Figure 2B). This is due to higher production of plant biomass by the soybean, corn, millet and velvet bean crops when fertilized with $\mathrm{P}$, as observed by Nunes et al. (2011) in the same experiment. Furthermore, in the area with no phosphorus fertilization, $\mathrm{P}$ was exported by the crops during harvest, which reduces the $\mathrm{P}$ level in the soil, because $\mathrm{P}$ is not replaced, thus reducing the grain yield and the plant biomass input in the soil (Nunes et al., 2011).

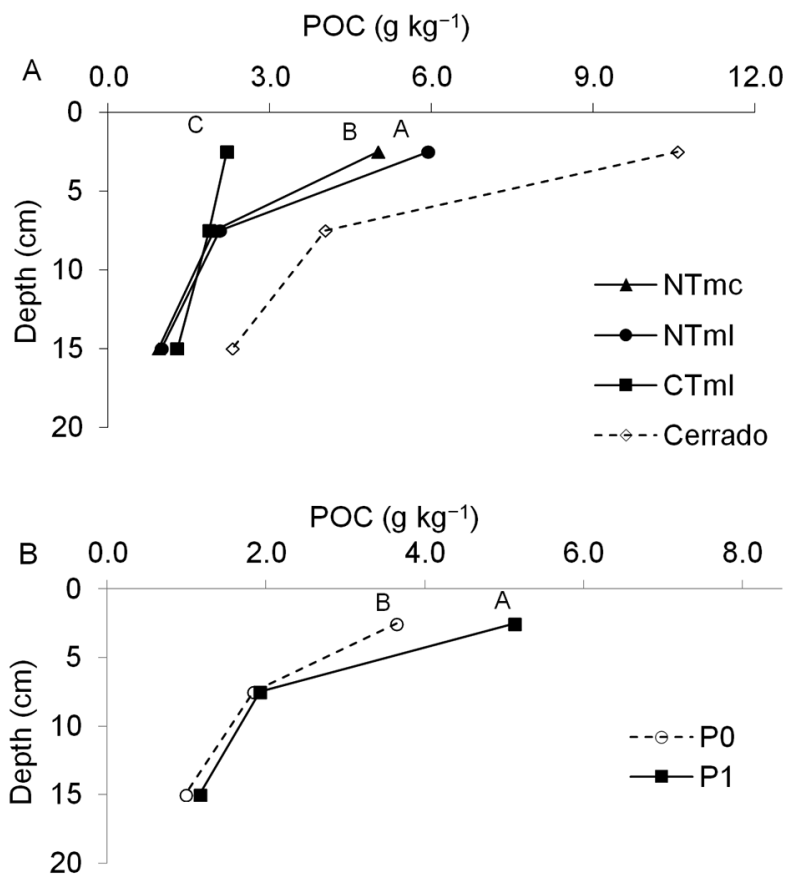

Figure 2 - Distribution of particulate organic carbon (POC) as a function of soil depth of an Oxisol under different management systems (A) (conventional tillage system with millet - CTml, notillage system with millet - NTml, no-tillage system with velvet bean - NTmc and native Cerrado vegetation as reference) and doses of phosphorus (B) (P0 and P1: 0 and $100 \mathrm{~kg} \mathrm{ha}^{-1} \mathrm{yr}^{-1}$ of $\mathrm{P}_{2} \mathrm{O}_{5}$, respectively). Means with equal letters between systems and $P$ doses at the same depth do not differ by Tukey's test $(p<0.05)$. 
In the 0.0-0.05 m layer, CMOL levels were ranked as follows: NTml $>$ NTmc $=\mathrm{CTml}$, which indicates that this fraction has a relatively short cycle and is very sensitive to changes due to soil management practices (Tirol-Padre and Ladha, 2004) particularly in the upper soil layers. Demetrio et al. (1998) observed that the effect of incorporating residues in the soil on the $\mathrm{C}$ content is significant for the CMOL fraction, and the speed and degree of transformation of the CMOL fraction depend on its chemical characteristics when the other factors remain constant.

In the $0.05-0.10 \mathrm{~m}$ layer, in turn, the CMOL fraction was not affected by the different management systems. As shown for the $\mathrm{C}-\mathrm{KMnO}_{4}$ and POC fractions, CMOL is probably associated with a greater amount of crop residue deposited on the soil surface by millet, which has greater accumulation under a no-tillage system (Nunes et al., 2011).

In contrast, in the $0.10-0.20 \mathrm{~m}$ layer, the CTml presented a higher CMOL content than the no-tillage systems, demonstrating the effect of incorporation of the organic residue via plowing. The $\mathrm{P}$ dosage had no effect on the CMOL content.

In addition to reducing the level of organic carbon (Table 1), the replacement of the native Cerrado vegetation by agricultural production also reduced the level of the labile SOM fractions. However, the adoption of the NTml in the Cerrado area increased the level of the CMOL fraction by $64 \%$ in the 0.0-0.05 m layer compared to CTml (Figure 3), demonstrating that millet associated with corn-soybean succession, regardless of the $\mathrm{P}$ rate, favored the accumulation of CMOL in the upper soil layers.

Under the no-tillage system, the MBC levels were higher than in the CT in the two uppermost soil layers, and no differences were observed between the management systems in the 0.10-0.20 m layer. For cover crops under NTml, the MBC values were higher than with velvet bean in the 0.0-0.05 $\mathrm{m}$ layer, indicating that grass as

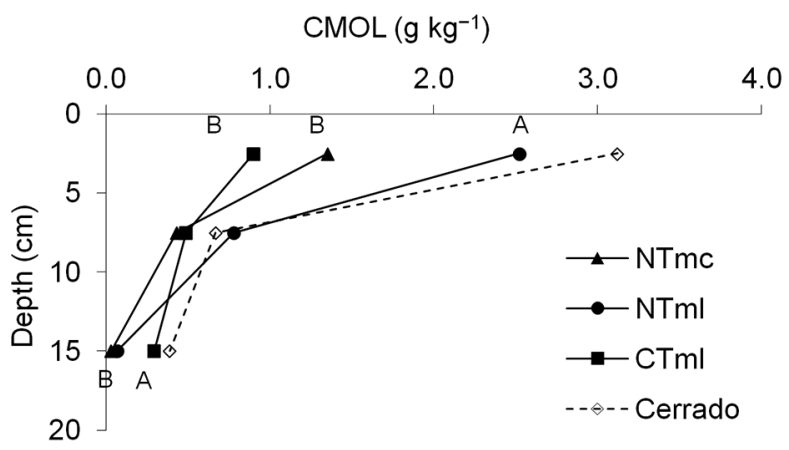

Figure 3 - Distribution of light organic matter carbon as a function of soil depth of an Oxisol under different management systems (conventional tillage system with millet - CTml, no-tillage system with millet - NTml, no-tillage system with velvet bean - NTmc and native Cerrado vegetation as reference). Means with equal letters between systems at the same depth do not differ by Tukey's test $(p<0.05)$. a cover crop provided a greater amount of soil surface residue, favoring an environment more suitable for microbial activity (Figure 4A).

In general, conservational management systems such as NT have higher MBC levels, and this parameter is negatively affected when the soil is disturbed, as observed by other authors in Cerrado soils (Figueiredo et al., 2010; Figueiredo et al., 2013). Additionally, higher aeration and organic residue incorporation due to soil disturbance, such as occurred in the $\mathrm{CT}$, can at first increase the MBC level but over time, the rapid decomposition of the litter can have a detrimental effect on the microbial population (Nunes et al., 2011).

Although restricted to the 0.0-0.05 m layer, $\mathrm{P}$ application increased the MBC content because of the higher availability of labile SOM, which is the primary energy source for the microorganisms (Figure 4B).

POC and MBC were the fractions most affected (reduced) in the upper soil layer by using a native vegetation area for agricultural purposes, with losses of $71 \%$ and $73 \%$, respectively, under CTml (Figures $2 \mathrm{~A}$ and $4 \mathrm{~A}$ ). According to Lopes et al. (2013), in the Cerrado region, the MBC levels in soils cultivated with grain are low, even under the best management practices.
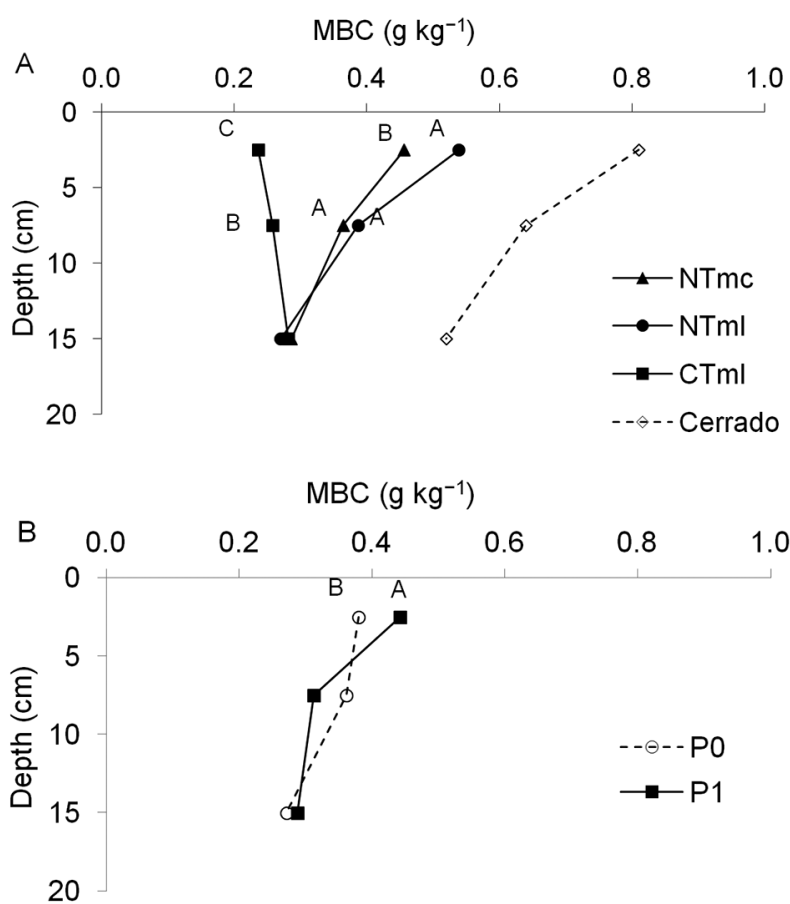

Figure 4 - Distribution of microbial biomass carbon (MBC) as a function of soil depth of an Oxisol under different management systems (A) (conventional tillage system with millet - CTml, notillage system with millet - NTml, no-tillage system with velvet bean - NTmc and native Cerrado vegetation as reference) and doses of phosphorus (B) (PO and P1: 0 and $100 \mathrm{~kg} \mathrm{ha}^{-1} \mathrm{yr}^{-1}$ of $\mathrm{P}_{2} \mathrm{O}_{5}$, respectively). Means with equal letters between systems and $P$ doses at the same depth do not differ by Tukey's test $(p<0.05)$. 


\section{Relationships between labile fractions of soil organic carbon}

The percentages of the different labile fractions with respect to organic carbon were very different, ranging from 0 to $33 \%$ (Table 2). The POC represented, on average, the highest percentage $(14 \%)$ of the OC because of the nature of the particle size analysis used to determine this fraction. In this case, the soil was completely dispersed by a treatment with a dispersing agent (hexametaphosphate) and mechanical agitation, to prevent aggregates from remaining intact in the coarser fractions, which allowed for the determination of the entire particulate organic matter inside and between the soil aggregates (Roscoe and Buurman, 2003).

The CMOL accounted for approximately $4 \%$ of the OC and $30 \%$ of the POC. This fraction represents the free OC in the soil, deposited on the surface of the aggregates, and is the most easily accessible fraction for microorganisms with a short residence time in the soil that ranges from 1 to 5 years (Janzen et al., 1992).

Owing to the good relationship between the POC and CMOL fractions (Table 3) it can be inferred that the CMOL represents the portion of the POC outside of the soil aggregates. Moreover, in the present study, because CMOL represented only $30 \%$ of the POC, most of the particulate organic matter in this Oxisol is, supposedly, inside soil aggregates.

The labile fraction with the lowest value and percentage was the MBC, which on average was $2 \%$ of the OC. This fraction is extremely sensitive and considered the active fraction of SOM (Costa et al., 2013). Studies indicate, on a scale of decreasing sensitivity, that the microbial soil biomass was highly variable and sensitive and was the active compartment of the organic carbon

Table 2 - Percentages of labile fractions in relation to total organic carbon in different layers of an Oxisol cultivated under different management systems and in Cerrado native vegetation.

\begin{tabular}{|c|c|c|c|c|}
\hline Depth (m) & NT velvet bean & NT millet & CT millet & Cerrado \\
\hline & \multicolumn{4}{|c|}{ POC/OC (\%) } \\
\hline $0.0-0.05$ & 24.5 & 26.0 & 13.5 & 33.0 \\
\hline $0.05-0.10$ & 12.0 & 11.5 & 12.0 & 19.3 \\
\hline \multirow[t]{2}{*}{$0.10-0.20$} & 7.0 & 7.0 & 8.5 & 15.2 \\
\hline & \multicolumn{4}{|c|}{$\mathrm{C}-\mathrm{KMnO}_{4} / \mathrm{OC}(\%)$} \\
\hline $0.0-0.05$ & 13.0 & 13.0 & 10.5 & 10.4 \\
\hline $0.05-0.10$ & 12.0 & 10.5 & 12.0 & 10.9 \\
\hline \multirow[t]{2}{*}{$0.10-0.20$} & 10.5 & 9.0 & 11.0 & 10.0 \\
\hline & \multicolumn{4}{|c|}{ CMOL/OC (\%) } \\
\hline $0.0-0.05$ & 6.5 & 11.0 & 5.5 & 7.8 \\
\hline $0.05-0.10$ & 2.5 & 4.5 & 3.0 & 3.2 \\
\hline \multirow[t]{2}{*}{$0.10-0.20$} & 0.0 & 0.5 & 2.0 & 2.2 \\
\hline & \multicolumn{4}{|c|}{$\mathrm{MBC} / \mathrm{OC}(\%)$} \\
\hline $0.0-0.05$ & 2.0 & 2.0 & 1.5 & 3.2 \\
\hline $0.05-0.10$ & 2.5 & 2.0 & 2.0 & 3.5 \\
\hline $0.10-0.20$ & 2.5 & 2.0 & 2.0 & 3.1 \\
\hline
\end{tabular}

$\mathrm{CT}$ : conventional tillage system; NT: no-tillage system. OC: total organic carbon; POC: particulate organic carbon; $\mathrm{C}-\mathrm{KMnO}_{4}$ : oxidizable $\mathrm{C}$ by solution of $\mathrm{KMnO}_{4} 0.033 \mathrm{~mol} \mathrm{~L}{ }^{-1}$; CMOL: light organic matter carbon; MBC: microbial biomass carbon dynamics, followed by light organic matter which had an intermediate sensitivity (Rovira et al., 2010).

All of the labile fractions obtained by the different methods had positive and significant correlations, with r-values above 0.68. Wendling et al. (2008) also found positive correlations between the $\mathrm{POC}$ and $\mathrm{C}-\mathrm{KMnO}_{4}$ fractions.

The fraction that best correlated with the POC was $\mathrm{C}-\mathrm{KMnO}_{4}(\mathrm{r}=0.90)$. The lowest correlation between labile carbon fractions occurred in the MBC fraction. This fraction is composed of a very limited set of substances and biomolecules compared to plant residue and other constituents of the other soil organic carbon labile fractions.

$\mathrm{C}-\mathrm{KMnO}_{4}$ was found to be a suitable indicator of the organic carbon labile fraction, given its methodological facility and sensitivity to the management system and applied $\mathrm{P}$ rate.

\section{Carbon Management Index}

The carbon management index for all of the management systems was lower than that for the native Cerrado (reference) (Figure 5). The combination of no-tillage

Table 3 - Pearson correlation coefficients between labile fractions of soil organic carbon at the 0.0-0.20 m depths (weighted average of the assessed layers), regardless of the system and $\mathrm{P}$ application rate.

\begin{tabular}{llllll}
\multicolumn{1}{c}{ rate. } & $\mathrm{OC}$ & ${\mathrm{C}-\mathrm{KMnO}_{4}}$ & $\mathrm{CMOL}$ & $\mathrm{MBC}$ & $\mathrm{POC}$ \\
\hline $\mathrm{OC}$ & 1.00 & & & & \\
$\mathrm{C}-\mathrm{KMnO}_{4}$ & $0.91^{* * *}$ & 1.00 & & & \\
$\mathrm{CMOL}$ & $0.86^{* * *}$ & $0.80^{* * *}$ & 1.00 & & \\
$\mathrm{MBC}$ & $0.79^{* * *}$ & $0.74^{* * *}$ & $0.68^{* * *}$ & 1.00 & \\
$\mathrm{POC}$ & $0.92^{* * *}$ & $0.90^{* * *}$ & $0.87^{* * *}$ & $0.77^{* * *}$ & 1.00 \\
\hline
\end{tabular}

OC: total organic carbon; POC: particulate organic carbon; C-KMnO $: \mathrm{C}$ oxidizable by solution of $\mathrm{KMnO}_{4} 0.033 \mathrm{~mol} \mathrm{~L}^{-1} ; \mathrm{CMOL}$ : light organic matter carbon; MBC: microbial biomass carbon. $\mathrm{n}=3$; ${ }^{* * *}$ significant at $p<0.001$.

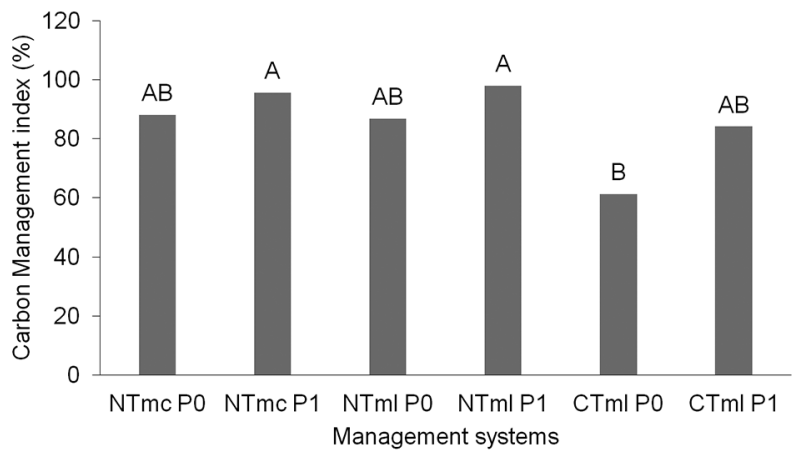

Figure 5 - Carbon management index at 0-0.10 m soil layer of an Oxisol under different management systems (conventional tillage system with millet - CTml, no-tillage system with millet - NTml, no-tillage system with velvet bean - NTmc and native Cerrado vegetation as reference) and doses of phosphorus ( $\mathrm{PO}$ and $\mathrm{P} 1$ : 0 and $100 \mathrm{~kg} \mathrm{ha}^{-1} \mathrm{yr}^{-1}$ of $\mathrm{P}_{2} \mathrm{O}_{5}$, respectively). Means with equal letters do not differ by Tukey's test $(p<0.05)$. 
with P fertilizer, regardless of the cover crop, promoted a higher $\mathrm{CMI}$ than the conventional system without $\mathrm{P}$ application. While the CTml P0 treatment was $40 \%$ lower than the CMI, the NTml P1 treatment had CMI values close to those of the native Cerrado. These results indicate that CT decreased not only the OC level but also the quality of the SOM, mainly with regard to its lability. In addition, these results demonstrate the higher capacity of the no-tillage system associated with $\mathrm{P}$ fertilization to preserve and enhance the quality of the soil organic matter.

The results confirm the utility of the CMI as a tool to evaluate soil quality as affected by management systems in the Cerrado. Vieira et al. (2007) found a positive relationship between the CMI and the physical, chemical and biological indicators of soil quality. Increases in CMI were also obtained in other studies as a result of practices such as the addition of organic matter via compost and sludge (Nogueirol et al., 2014), legume-based cropping systems and the addition of mineral $\mathrm{N}$ (Vieira et al., 2007), and green cane trash management (Blair et al., 1995).

\section{Conclusions}

The labile fractions were found to be sensitive to soil management practices, and the lowest levels of these parameters were observed under a conventional tillage system. The primary changes occurred in the surface soil layer $(0.0-0.05 \mathrm{~m})$, where in general the use of a notillage system with millet as the cover crop showed the highest carbon values in the studied fractions. P fertilization for eleven years did not change the total organic carbon, but promoted the accumulation of $\mathrm{C}-\mathrm{KMnO}_{4^{\prime}}$ particulate organic carbon and microbial biomass carbon in the soil, regardless of soil management system and cover crop. A positive correlation was observed between the various labile fractions, as well as between these fractions and the total organic carbon in the soil. P fertilizer application improved the capacity of the notillage system to promote soil quality, as assessed by the carbon management index. Our results confirm that the carbon management index is an appropriate and sensitive parameter for the assessment of changes promoted by soil management systems in the Cerrado.

\section{References}

Aguiar, A.C.F.; Cândido, C.S.; Carvalho, C.S.; Monroe, P.H.M.; Moura, E.G. 2013. Organic matter fraction and pools of phosphorus as indicators of the impact of land use in the Amazonian periphery. Ecological Indicators 30: 158-164.

Alvares, C.A.; Stape, J.L.; Sentelhas, P.C.; Gonçalves, J.L.M.; Sparovek, G. 2013. Koppen's climate classification map for Brazil. Meteorologische Zeitschrift 22: 711-728.

Blair, G.J.; Lefroy, R.D.B.; Lisle, L. 1995. Soil carbon fractions based on their degree of oxidation, and the development of a carbon management index for agricultural systems. Australian Journal of Agricultural Research 46: 1459-1466.
Cambardella, C.A.; Elliott, E.T. 1992. Particulate soil organic matter changes across a grassland cultivation sequence. Soil Science Society of America Journal 56: 777-783.

Campos, B.H.C.; Amado, T.J.C.; Bayer, C.; Nicoloso, R.S.; Fiorin, J.E. 2011. Carbon stock and its compartments in a subtropical oxisol under long-term tillage and crop rotation systems. Revista Brasileira de Ciência do Solo 35: 805-817.

Costa, A.R.; Sato, J.H.; Ramos, M.L.G.; Figueiredo, C.C.; Souza, G.P.; Rocha, O.C.; Guerra, A.F. 2013. Microbiological properties and oxidizable organic carbon fractions of an oxisol under coffee with split phosphorus applications and irrigation regime. Revista Brasileira de Ciência do Solo 37: 55-65.

Figueiredo, C.C.; Resck, D.V.S.; Carneiro, M.A. 2010. Labile and stable fractions of soil organic matter under management systems and native cerrado. Revista Brasileira de Ciência do Solo 34: 907-916.

Figueiredo, C.C.; Resck, D.V.S.; Carneiro, M.A.; Ramos, M.L.G.; Sá, J.C.M. 2013. Stratification ratio of organic matter pools influenced by management systems in a weathered Oxisol from a tropical agro-ecoregion in Brazil. Soil Research 51: 133-141.

Haynes, R.J. 2005. Labile organic matter fractions as central components of the quality of agricultural soils: an overview. Advances in Agronomy 85: 221-268.

Janzen, H.H.; Campbell, C.A.; Brandt, S.A.; Lafond, G.P.; Townleysmith, L. 1992. Light-fraction organic matter in soils from long-term crop rotations. Soil Science Society of America Journal 56: 1799-1806.

Joergensen, R.G. 1996. The fumigation-extraction method to estimate soil microbial biomass: calibration of the $\mathrm{k}_{\mathrm{ec}}$ value. Soil Biology and Biochemistry 28: 25-31.

Li, Z.; Zhao, B.; Wang, Q.; Cao, X.; Zhang, J. 2015. Differences in chemical composition of soil organic carbon resulting from long-term fertilization strategies. Plos One 10: 1-14.

Loss, A.; Pereira, M.G.; Costa, E.M.; Beutler, S.J. 2014. Soil fertility, physical and chemical organic matter fractions, natural ${ }^{13} \mathrm{C}$ and ${ }^{15} \mathrm{~N}$ abundance in biogenic and physicogenic aggregates in areas under different land use systems. Soil Research 52: 685-697.

Lopes, A.A.C.; Sousa, D.J.M.; Chaer, G.M.; Reis Junior, F.B.; Goedert, W.J.; Mendes, I.C. 2013. Interpretation of microbial soil indicators as a function of crop yield and organic carbon. Soil Science Society of America Journal 77: 461-472.

Nelson, D.W.; Sommers, L.E. 1996. Total carbon, organic carbon, and organic matter. p. 961-1010. In: Black, C.A., ed. Methods of soil analysis. Part 3. Chemical methods. Soil Science Society of America, Madison, WI, USA.

Nogueirol, R.C.; Cerri, C.E.P.; Da Silva, W.T.L.; Alleoni, L.R.F. 2014. Effect of no-tillage and amendments on carbon lability in tropical soils. Soil and Tillage Research 143: 67-76.

Nunes, R.S.; Lopes, A.A.C.; Sousa, D.M.G.; Mendes, I.C. 2011. Management systems and the carbon and nitrogen stocks of cerrado oxisol under soybean-maize succession. Revista Brasileira de Ciência do Solo 35: 1407-1419 (in Portuguese, with abstract in English).

Quanying, W.; Yang, W.; Qicun, W.; Jingshuang, L. 2014. Impacts of 9 years of a new conservational agricultural management on soil organic carbon fractions. Soil and Tillage Research 143: $1-6$. 
Rangel, O.J.P.; Silva, C.A.; Guimarães, P.T.G.; Guilhermes, L.R.G. 2008. Oxidizable organic carbon fractions in a latosol cultivated with coffee at different planting spacings. Ciência e Agrotecnologia 32: 429-437 (in Portuguese, with abstract in English).

Roscoe, R.; Buurman, P. 2003. Tillage effects on soil organic matter dynamics in density fractions of a cerrado Oxisol. Soil and Tillage Research 70: 107-119.

Rovira, P.; Jorba, M.; Romanyà, J. 2010. Active and passive organic matter fractions in Mediterranean forest soils. Biology and Fertility of Soils 46: 355-369.

Schiavo, J.A.; Busato, J.G.; Martins, M.A.; Canellas, L.P. 2009. Recovery of degraded areas revegetated with Acacia mangium and Eucalyptus with special reference to organic matter humification. Scientia Agricola 66: 353-360.

Soil Survey Staff. 2006. Keys to Soil Taxonomy. USDA-SCS, Washington, DC, USA.

Sousa, D.M.G.; Lobato, E. 2004. Cerrado: Soil Correction and Fertilization = Cerrado: Correção do Solo e Adubação. 2ed. Embrapa Cerrados, Planaltina, DF, Brazil (in Portuguese).

Tirol-Padre, A.; Ladha, K.J. 2004. Assessing the reliability of permanganate-oxidizable carbon as an index of soil labile carbon. Soil Science Society of America Journal 68: 969-978.
Vance, E.D.; Brookes, P.C.; Jenkinson, D.S. 1987. An extraction method for measuring soil microbial biomass carbon. Soil Biology and Biochemistry 19: 703-707.

Vieira, F.C.B.; Bayer, C.; Zanatta, J.A.; Dieckow, J.; Mielniczuk, J.; He, Z.L. 2007. Carbon management index based on physical fractionation of soil organic matter in an Acrisol under longterm no-till cropping systems. Soil and Tillage Research 96: 195-204.

von Lützow, M.; Kögel-Knabner, I.; Ekschmitt, K.; Flessa, H.; Guggenberger, G.; Matzner, E.; Marschner, B. 2007. SOM fractionation methods: relevance to functional pools and to stabilization mechanisms. Soil Biology and Biochemistry 39: 2183-2207.

Walkley, A.; Black, J.A. 1934. An examination of the degtjareff method for determining soil organic matter and a proposed modification of the chromic titration method. Soil Science 37: 29-38.

Wendling, B.; Juncksch, I.; Mendonça, E.S.; Neves, I.C.L.; Silva, I.R.; Costa, L.M. 2008. Organic-mater lability and carbonmanagement indexes in agrosilvopasture system on Brazilian Savannah. Communications Soil Science Plant Analysis 39: 1750-1772. 